\title{
A ABSTRATIVIZAÇÃO DO CONTROLE DIFUSO CONSTITUCIONAL E SUAS CONSEQUÊNCIAS NO ORDENAMIENTO JURÍDICO BRASILEIRO
}

\author{
Paulo Bruno Rodrigues Domingos \\ Concludente do curso de Especialização em Direito Processual \\ (FA7). Advogado. \\ adv.paulobruno@gmail.com
}

Sumário: Introdução. 1. Do Surgimento do controle de constitucionalidade. 2 . Do controle abstrato de constitucionalidade. 3. Do controle difuso de constitucionalidade. 4. Os efeitos da súmula vinculante. 5. O controle difuso-incidental e sua "abstrativização". Considerações finais. Referências.

Resumo: Diante do julgamento do Mandando de Injunção 4335-5 AC, o ministro relator Gilmar Ferreira Mendes propôs que fosse dada a sua decisão os efeitos vinculantes. Com isso abriu-se a discussão da possibilidade de utilizar no sistema de Controle Constitucional Difuso os mesmo efeitos gerados pelas decisões do Controle Concentrado Constitucional, cuja lei específica regulamenta prevê tais efeitos. Argumenta-se sobre esta possibilidade como forma de agilizar o sistema judiciário brasileiro. Diante disto é que surge na doutrina os questionamento sobre a aceitação ou não deste novo instituto no Direito Constitucional Brasileiro.

Palavras chave: Controle Constitucional. Controle Concentrado. Controle Difuso. Abstrativização.

\section{INTRODUÇÃO}

É cediço que a Carta Política brasileira possui uma rigidez no que tange à modificação de suas normas, que foram construídas pelo legislador constituinte originário para que a ideia defendida pelo Estado Democrático de Direito não fosse passível de modificações pelo simples alvedrio do legislador constituinte secundário, bem como chega a possuir cláusulas pétreas. Para tanto, formulou-se um processo diferenciado de reforma constitucional garantindo, assim, a efetividade desta rigidez.

A Constituição Federal de 1988 trouxe positivada duas formas de controle de constitucionalidade, e por tal motivo é considerada, já que mesclou dois sistemas de controle criados por ordenamentos jurídicos diferentes.

Ocorre que a Constituição Brasileira, ao incluir em seu ordenamento jurídico estes sistemas, já o fez definindo as suas diferenças e traçando o procedimento adequado quando do questionamento de inconstitucionalidade por um ou outro sistema.

Dentre estes quesitos, quando falar-se de Controle Difuso de Constitucionalidade, encontra-se a necessidade do envio de uma mensagem ao Senado Federal para que este suspenda a execução da norma, como afirma o art. 52, X da Lei Maior.

Porém, diante das teorias constitucionais contemporâneas, o Supremo Tribunal Federal tem tentado cada vez mais expurgar este requisito e proferido em sede de Controle Difuso, os efeitos típicos do Controle Abstrato. 
Com isso, surge a "abstrativização do Controle Difuso", bastante defendida pelo Ministro Gilmar Ferreira Mendes. Sua argumentação baseia-se na possibilidade de modificar a Constituição Federal apenas com a simples interpretação da norma.

Sob este prisma, começa-se a discutir acerca do tema para demonstrar de forma humilde alguns aspectos julgados relevantes, bem como as críticas necessárias.

A compreensão das implicações que o referido tema trará ao ordenamento jurídico brasileiro mostra-se de total relevância, uma vez que é através deste debate que se conseguirá sedimentar a ideia.

Somente através da exposição dos argumentos que defendem a tese, bem como os contrários ao seu uso é que possibilitarão ao leitor formar seu próprio juízo sobre o tema. É com este desejo que se tentará discutir acerca do assunto.

Perfazendo uma análise superficial do tema escrito, tentar-se-á responder aos seguintes questionamentos:

- Como e quais são os Controles de Constitucionalidade adotados pela Constituição Federal do Brasil?

- Em que consiste a Teoria da Abstrativização do Controle Difuso de Constitucionalidade?

- Quais as consequências jurídicas da utilização desta teoria?

\section{Do SURGIMENTO DO CONTROLE DE CONSTITUCIONALIDADE}

Diante do poder emanado pelo constitucionalismo e suas derivações, que decorrem da transformação das intenções populares em lei, qual seja, a Constituição, é necessário que se tenha em mente uma forma de proteger o poder supremo da constituição enquanto norma maior de um estado.

Destarte, o próprio poder constituinte originário formula mecanismos de controlar e deter qualquer outra norma que, ao entrar em conflito com a Lei Maior, seja afastada de forma plena. Com muita propriedade, o douto Pedro Lenza (2004, p.83) mostra que:

A ideia de controle, então, emanada da rigidez, pressupõe a noção de um escalonamento normativo, ocupando a Constituição o grau máximo na aludida relação hierárquica, caracterizando-se como norma de validade para os demais atos normativos do sistema.

Foi a partir desse pensamento que começou a se desenvolver o sistema de controle de constitucionalidade, pois, para que pudesse se combater um afronta à Constituição, precisaria de procedimentos também já positivados que definissem o rito, como bem apregoa o Estado Democrático de Direito.

Nesta perspectiva, criaram-se dois mecanismos de controle das leis infraconstitucionais. De um lado, foi originado o sistema de controle a partir do caso concreto, utilizado pela jurisdição norte-americana; e de outro, o controle feito na lei ainda em tese nascido no sistema austríaco.

Foi no célebre caso Marbury versus Madison que a Corte americana utilizou-se da interpretação para mostrar se havia ou não confronto entre a lei a Constituição. Ocorre que a jurisdição norte-americana é baseada em um sistema consuetudinário, ou seja, o common law, isso implica afirmar que somente após o caso concreto é que se diz o direito. Portanto, neste sistema, o direito vem por interpretação dos fatos e dos costumes. 
Daí é que se fala que o controle de constitucionalidade é concreto; por assim dizer, só é feita a análise de inconstitucionalidade no caso concreto.

Ao revés, Hans Kelsen desenvolveu a sua teoria da norma hipotética fundamental e a implantou no sistema austríaco. Sua ideia era a de que sendo a Constituição a lei maior de um país, ela não poderia estar em conflito com nenhuma lei que lhe fosse inferior. No entanto, na Áustria, o sistema jurisdicional é o civil law; a saber, a lei nasce antes dos fatos. Neste sistema, a lei é formada para ser aplicada ao caso concreto, então há um ordenamento jurídico pré-existente.

Assim, a análise que ele propôs seria um estudo da lei em tese, antes de ser aplicada, pois caso fosse entendido pela Tribunal Austríaco que a lei estivesse em conflito com a Constituição, aquela era de plano afastada, ou seja, não poderia ser usada no caso concreto. Daí é que se intitulou o sistema austríaco em controle de constitucionalidade abstrato.

Outra diferença destes dois controles é que no modelo norte-americano todo o poder judiciário pode fazer a análise e proferir seu entendimento pelo inconstitucionalidade, afastando a norma no caso concreto. Já no modelo austríaco, somente o Tribunal Constitucional tem poder para declarar a não conformidade da lei com a constituição e, por consequência, afastar a norma do ordenamento.

No Brasil, desde a Constituição de 1896, o controle de constitucionalidade foi usado positivado na Lei Maior.

Atualmente a Constituição brasileira possui um modelo ímpar de controle, pois há a possibilidade de se exercer os dois controles, quais sejam o controle em abstrato e o controle concreto.

\section{Do CONTROLE ABSTRATO DE CONSTITUCIONALIDADE}

Portanto, o sistema jurisdicional brasileiro pode, em qualquer grau de jurisdição, declarar a inconstitucionalidade de uma norma para não aplicá-la ao caso concreto, como também pode o Supremo Tribunal Federal analisar uma norma em tese e proferir sua inconstitucionalidade.

Insta salientar que o termo inconstitucionalidade é apenas o gênero das normas que estão em desconformidade com a constituição.

Desta forma, inconstitucional é toda a norma que direta ou indiretamente apregoa aquilo que é inverso ao que está descrito na lei maior. Assim, ao fazer uma análise da lei, deve-se ter a ciência de que se for fazer uso da norma estará afastando o uso da constituição.

É por tal motivo que se diz que a inconstitucionalidade é apenas o gênero, pois diante do explanado tem-se vários desdobramentos, a saber: a inconstitucionalidade total ou parcial; por ação ou por omissão; material ou formal; originária ou superveniente.

O que se demonstra é que o controle de constitucionalidade se dá na norma como um todo, desde a sua criação, como se argui quando do sistema de votação escolhido até a interpretação que deverá se ter da norma para que esta não perca sua eficácia.

A Constituição Federal de 1988 traz em seu artigo 102,I a competência do Supremo Tribunal Federal para processar e julgar a Ação Direta de Inconstitucionalidade (ADI). Tal ação tem uma lei específica (Lei n ${ }^{\circ}$ 9.868/99), que define os legitimados ativos, possibilidade de medida liminar, bem como os efeitos da sentença transitada em julgado, assim descrito:

Art. 28. Dentro do prazo de dez dias após o trânsito em julgado da decisão, o Supremo Tribunal Federal fará publicar em seção especial do Diário da Justiça e do Diário Oficial da União a parte dispositiva do acórdão. 
Parágrafo único. A declaração de constitucionalidade ou de inconstitucionalidade, inclusive a interpretação conforme a Constituição e a declaração parcial de inconstitucionalidade sem redução de texto, têm eficácia contra todos e efeito vinculante em relação aos órgãos do Poder Judiciário e à Administração Pública federal, estadual e municipal.

Ocorre que, como definido na própria Lei $n^{\circ}$ 9.868/99, a sentença de uma ADI após sua publicação, produzirá efeitos vinculantes e erga omnes, isso implica dizer que a partir daquela sentença, a norma será afastada do ordenamento jurídico e não poderá ser mais usada.

É sob este ângulo que se diz vinculante, pois tal sentença vincula todo o sistema jurídico, uma vez que a norma atacada não mais servirá como defesa. E, portanto, não poderá ser questão de discussão, ou seja, o efeito é para todos (erga omnes).

Há que se falar também do efeito ex tunc, pois na ADI o que se questiona é uma afronta de uma lei inferior à Constituição. Assim, analisados os fatos e proferida a decisão que torna a norma inconstitucional, esta deverá ser retirada do mundo jurídico bem como todos os seus desdobramentos.

Entende-se que, se a norma é considerada inconstitucional, esta jamais deveria existir, sendo assim todos os atos praticados a partir de interpretação da norma também não existirão, uma vez que desde sua origem esta já continha vício e não poderia em tempo algum sobreviver divergindo com a Carta Política, o que se chama de efeito ex tunc.

\section{Do CONTROLE DIFUSO DE CONSTITUCIONALIDADE}

Por outro lado, influenciado pela Constituição Norte-Americana, o Brasil adotou o sistema de controle de constitucionalidade difuso onde, a partir do questionamento em um caso concreto, o Poder Judiciário poderá analisar a questão e proferir uma sentença de inconstitucionalidade e, assim, afastar a norma para o referido caso apreciado.

Cumpre esclarecer que este controle foi criado nos Estado Unidos da América por consequência da falta de confiança que existia entre o Poder Judiciário e o Poder Legislativo, haja vista, que antes de sua proclamação como república, o povo norte-americano estava sujeito à legislação de sua metrópole e sua Suprema Corte era tipicamente política, sendo os cargos escolhidos pelo Executivo, o que de certa forma fazia com que suas decisões fossem tendenciosas.

Após a união das 13 Colônias e a sua transformação em República, o Poder Judiciário teve, dentre as suas atividades, a possibilidade de analisar as leis infraconstitucionais, como foi abordado anteriormente quando falou-se no famoso caso Marbury versus Madison, que iniciou esta prática no referido país.

Este sistema norte-americano baseia-se na possibilidade do controle ser difundido em todo o Poder Judiciário, possibilitando ao magistrado fazer sua própria interpretação constitucional da lei atacada e, mediante devida fundamentação, julgar uma norma inconstitucional.

Como neste sistema o magistrado tem o poder de proferir a inconstitucionalidade de uma lei, diz-se que o sistema é difuso.

Tal controle ou fiscalização se dá ao propor um incidente de inconstitucionalidade em sede de recurso na segunda instância ou como preliminar da petição inicial da ação proposta.

Então, o juiz será responsável pela apreciação do questionamento levantado, proferindo seu entendimento interpretativo na decisão. Tal discussão poderá ser levada até o Supremo Tribunal Federal através de um Recurso Extraordinário. 
No que concerne aos efeitos produzidos pela sentença, estes serão apenas inter partes e ex nunc. Ou seja, é dado a este controle incidental em caso concreto o efeito vinculante apenas aqueles que compõem o lide, bem como seus efeitos só passarão a vigorar no momento da decisão em diante.

\section{OS EFEITOS DA SÚMULA VINCULANTE}

Com a edição da Emenda Constitucional no 45/2004, muito conhecida como a reforma do judiciário, esta inovou modificando alguns institutos dispostos na Constituição Federal por força do poder constituinte secundário.

$\mathrm{Na}$ nova redação dada pela referida emenda o artigo 103-A criou a possibilidade de criação de súmulas com efeitos vinculantes em matérias com reiterados julgados da mesma matéria constitucional.

Essa positivação foi mais uma norma que apenas regulamentou o que já havia se tornado prática. Sob a argumentação de uniformização de entendimentos acerca de matéria constitucional, criouse esta possibilidade do Supremo Tribunal Federal sumular seu entendimento com efeitos vinculantes para que não houvessem sentenças divergentes sobre a mesma matéria e por consequência sua subida até a última instância, uma vez que já tinha se tornado e notória a posição do STF.

É necessário lembrar que na aprovação da súmula vinculante, por votação qualificada, a referida súmula é criada com forma de lei e deverá ser usada tanto no âmbito do Poder Judiciário como pela Administração Pública.

Urge salientar que muito embora a súmula vinculante limite as sentenças dos juízes em determinadas matérias, nada impede que o magistrado - que, no caso concreto, analisando os fatos, entenda que sua aplicação não será de um todo constitucional - afaste sua aplicação e de forma bem fundamentada, demonstre que para o caso por ele analisado os requisitos não são de um todo semelhantes ao que aborda a súmula.

Após tecer estas breves considerações sobre os efeitos da súmula vinculante, passa-se agora a construir um posição sobre a abstrativização do controle difuso-incidental, demonstrando seus efeitos e as devidas opiniões.

\section{O CONTROLE DIFUSO-INCIDENTAL E SUA "ABSTRATIVIZAÇÃO"}

Como já exposto anteriormente, o controle difuso-incidental dá-se por meio de questionamento da constitucionalidade de uma norma aplicada em um caso concreto, onde o juiz a quo deverá se manifestar e decidir pela constitucionalidade ou inconstitucionalidade da norma questionada.

Por meio do sistema processual brasileiro, este questionamento poderá chegar até o Supremo Tribunal Federal e este proferir, em última instância, a decisão sobre a constitucionalidade ou não da norma.

Ocorre que como já escrito, os efeitos desta decisão proferida pela Suprema Corte brasileira só gera efeitos entre os litigantes no referido processo, devendo a decisão de inconstitucionalidade ser respeitada dali em diante, ou seja, serão válidos todos os efeitos que a lei produziu antes da sua arguição de constitucionalidade.

Para esta situação, a Constituição Federal (art. 52, X) prevê que após mensagem enviada à mesa do Senado Federal esclarecendo os motivos pelos quais foi declarada uma norma inconstitucional, compete ao Senado suspender a execução da lei declarada inconstitucional. 
Fazendo-se apenas uma leitura e análise superficial do artigo acima citado, percebese que a possibilidade de suspenção da execução de uma lei é função privativa do Senado Federal.

Porém, o Ministro Gilmar Ferreira Mendes, ao proferir seu voto como relator do Mandado de Injunção 4335-5/AC defendeu a tese de que o STF ao proferir decisão de inconstitucionalidade em sede de controle difuso-incidental, poderia a própria Corte declarar a inconstitucionalidade da lei com efeitos erga omnes. Fazendo com que coubesse ao Senado Federal apenas dar publicidade da decisão tomada pela Suprema Corte.

Seguindo o voto do relator, o ministro Eros Grau proferiu seu voto-vista defendendo o mesmo pensamento do Ministro Gilmar Mendes e reiterou que existe a possiblidade de tornar vinculante os efeitos de uma decisão tomada em controle difuso sem a expressa declaração pelo Senado Federal.

Esta tendência já foi anteriormente utilizada pelo Ministro Gilmar Mendes, que defende esta abstrativização do questionamento, que por assim dizer seria uma transcendência do questionamento exposto, o que permitiria julgar a norma objetivamente em defesa da Constituição Federal, como pode-se perceber no julgamento do Processo Administrativo 318.715:

\begin{abstract}
O recurso extraordinário 'deixa de ter caráter marcadamente subjetivo ou defesa de interesse das partes, para assumir, de forma decisiva, a função de defesa da ordem constitucional objetiva. Trata-se de orientação que os modernos sistemas de Corte Constitucional vêm conferindo ao recurso de amparo e ao recurso constitucional [...]

A função do Supremo nos recursos extraordinários - ao menos de modo imediato - não é a de resolver litígios de fulano ou beltrano, nem a de revisar todos os pronunciamentos das Cortes inferiores. O processo entre as partes, trazido à Corte via recurso extraordinário, deve ser visto apenas como pressuposto para uma atividade jurisdicional que transcende os interesses subjetivos.
\end{abstract}

É clara a intenção do Ministro Gilmar Mendes de defender um controle de constitucionalidade totalmente exclusivo do Supremo Tribunal Federal. Em que pese o ministro argumentar que o interesse maior é a preservação da ordem constitucional, esta também não pode ser feita fora dos limites estabelecidos pelo próprio legislador constituinte originário.

Foi neste sentido que começou a discussão acerca deste tema, que o professor Fredie Didier (2007, p.105) chamou de "abstrativização do controle difuso". Quis o referido professor explicar que o que poderia ocorrer era a aplicação dos efeitos do controle concentrado de constitucionalidade no controle difuso.

Para tanto, deve-se mostrar qual o sentido da palavra "abstrato" neste contexto. Esta deve ser entendida como a aplicação dos conceitos e noções utilizado no Controle de Constitucionalidade Abstrato, pois defende o Ministro Gilmar Mendes, seguido pelo Ministro Eros Grau, que a simples apreciação e votação sobre a inconstitucionalidade de uma norma em sede de Recurso Extraordinário poderia gerar os mesmos efeitos descritos no controle concentrado.

Tal afirmação pode ser vista em transcrição do voto no Ministro Eros Grau na Rcl 4335-5/AC, no qual o douto ministro sugere a modificação do texto constitucional, abaixo transcrito:

\footnotetext{
...passamos em verdade de um texto [pelo qual] compete privativamente ao Senado Federal suspender a execução, no todo ou em parte, de lei declarada inconstitucional por decisão definitiva do Supremo Tribunal Federal, a outro texto: "compete privativamente ao Senado Federal dar publicidade à suspensão da execução, operada pelo Supremo Tribunal Federal, de lei declarada inconstitucional, no todo ou em parte, por decisão definitiva do Supremo. (grifo nosso)
} 
Este argumento foi chamado pelo Ministro Gilmar Mendes de mutação constitucional, que em resumo seria a mudança na interpretação do texto constitucional para que se adequasse a um novo conceito ou prática constitucional, sem contudo, modificar o texto por via de emenda.

Clara está a impossibilidade desta modificação, haja vista que se isto ocorrer, será uma afronta direta aos princípios do Estado Democrático de Direito. Frise-se, é primordial no Estado de Direito que as normas sejam as regras que irão nortear todo e qualquer ato, pois como afirma o Joaquim José Gomes Canotilho, o surgimento do Estado de Direito cria o que ele intitulou de "Império do Direito".

É fato dizer que diante do Constitucionalismo materializado na Constituição Federal, cabe ao Estado seguir as normas criadas pelo poder constituinte originário. Portanto, não se vislumbra a possibilidade do Supremo Tribunal Federal alçar-se de uma função privativa, frise-se, do Senado da República, por simples entendimento de que ao proferir uma decisão esta não precisará de maiores procedimentos para ser acatada por todos.

Em recente artigo publicado pelo professor Martônio Mont'Alverne Barreto Lima (2007, p.7) em conjunto com outros professores foi exposta sua opinião com uma severa crítica a esta posição do Supremo Tribunal Federal de expandir os limites impostos pela própria Lei Maior brasileira, consoante o seguinte trecho:

Como se não bastasse reduzir a competência do Senado Federal a de um órgão de imprensa, há também uma consequência grave para o sistema de direitos e de garantias fundamentais. Dito de outro modo, atribuir eficácia erga onmes e efeito vinculante às decisões do STF em sede de controle difuso de constitucionalidade é ferir os princípios constitucionais do devido processo legal, da ampla defesa e do contraditório.

Percebe-se que os argumentos utilizados pelo professor são de grande importância e vão diretamente de encontro ao que aqui foi falado sobre o Estado Democrático de Direito.

O trecho citado revela a preocupação do professor em dar a oportunidade aos interessados para se manifestarem, e assim, respeitarem os direitos e garantias individuais.

Havendo a possibilidade da criação de efeitos vinculantes das decisões do STF em controle difuso sem a participação do Senado Federal, o que ocorrer estará desrespeitando completamente o Princípio da Separação de Poderes, uma vez que, se somente compete, de forma privativa, ao Senado Federal suspender a execução de lei ou ato normativo declarado inconstitucional pelo STF, este o faz antes daquele, é inegável a interferência do Poder Judiciário em atividade típica do Poder Legislativo.

Sendo assim, não haveria necessidade da existência do Controle Concentrado de Constitucionalidade, uma vez que havendo uma divergência entre o que está apregoado na Constituição e uma lei infraconstitucional bastaria no caso concreto o Supremo Tribunal Federal deferir a inconstitucionalidade arguida para que esta produzisse efeito contra todos e perdesse sua eficácia.

Demais a mais, é necessário se estabelecer uma diferença entre os dois Controles. No Controle Abstrato de Constitucionalidade, a lei ao ser questionada, esta é feita apenas baseada nos princípios e noções do Direito, não há qualquer interferência prática ainda. Sendo assim, ao se declarar a sua inconstitucionalidade a lei será nula, ou seja, a lei não poderia jamais ter existido em confronto com a Constituição, é sob esta ótica que tem os efeitos vinculantes e contra todos já positivados na lei específica para o Controle Concentrado. Ocorre que, em sede de Controle Difuso, a norma existe, é questionada e somente após a decisão do STF em um caso concreto é 
que a norma será desconsiderada para o referido caso, e desta forma, produzirá os efeitos apenas para as partes, retroagindo apenas no caso questionado. Porém, poderá o STF pedir que o Senado Federal estenda estes efeitos, suspendendo a execução da norma, o que é tido como perda de sua eficácia, daí, portanto, existir para este Controle Incidental no efeito ex nunc, implicando dizer que até o momento de suspenção a norma estava de acordo com a Constituição Federal.

Esclareça-se que a ideia da "abstrativização" encontra-se cada vez mais forte à medida que o STF profere decisões que impõem sua supremacia. Apenas para efeito didático, passa-se a elencar algumas das decisões proferidas pelo Pretório Excelso:

A Lei adjetiva Civil n ${ }^{\circ}$ 9.756/98 sofreu alterações que tratavam do impedimento de recurso que contraria súmula ou jurisprudência dominante nas Cortes. Assim não havendo nas razões recursais fundamento baseado em súmula do STF ou STJ ou seu posicionamento majoritário, este recurso não poderia subir.

Outra alteração incluída, mas felizmente já revogada, previa no Regimento Interno do próprio STF a vinculação de suas decisões para as Turmas Recursais da Justiça Federal.

No tocante à própria jurisprudência, o Ministro Gilmar Ferreira Mendes vem defendendo a utilização da "Teoria da Abstrativização", como se pode explicar no julgamento apertado de 6 x 5 votos do HC 82.959/99 para conferir eficácia erga omnes à pregressão de regime nos Crimes Hediondos; após o julgamento deste remédio constitucional, o Supremo Tribunal Federal vem admitindo Reclamação Constitucional com o fundamento de desrespeito de suas decisões.

Neste caso é que se tem a Rcl 4335/AC já falada anteriormente, onde a Defensoria Pública da União pede a progressão de regime para alguns presos sob o fundamento da Suprema Corte ter considerado inconstitucional o art. $2^{\circ}$ da Lei dos Crimes Hediondos. Novamente, como o Ministro-relator Gilmar Mendes reitera suas acepções do novo sistema constitucional através do direito comparado e entende que deve-se dar eficácia erga omnes ao HC 82.959/99.

Atualmente, o referido ministro também tem defendido esta tese em um Mandado de Injunção (MI 732-8) que refere-se ao direito de greve dos servidores públicos civis. Utiliza-se o Ministro Gilmar Mendes da Teoria da Abstrativização e apregoa que a Corte Constitucional deva alçar-se da Teoria Concretista geral para legislar neste caso.

Portanto, pode-se perceber que o Supremo Tribunal Federal cada vez mais abrange suas atribuições e pratica atos que não lhe são próprios.

Considerar que possa existir no ordenamento jurídico brasileiro a possibilidade do Supremo Tribunal Federal proferir decisões com efeitos erga omnes sem, contudo, operar com o devido procedimento descrito na própria Carta Política, é regredir na ótica dos princípios do Estado Democrático de Direito, bem como criar um ditadura onde o Poder Judiciário terá atribuições do antigo Poder Moderador.

Desconsiderar a função do Poder Legislativo de declarar a suspensão de uma norma sob a alegação de que o procedimento é apenas mais demorado para se chegar ao mesmo fim é tirar da cúpula de representantes do sistema democrático a anuência do povo das decisões que lhe serão impostas.

\section{ConsideraÇões FINAIS}

Diante destes questionamentos, chega-se diretamente a uma afronta ao Princípio da Separação de Poderes. 
Ocorre que o Supremo Tribunal Federal está tentando diminuir suas atividades como Corte Recursal e transformar-se apenas em Corte Constitucional, como já se havia falado nos mecanismos implantados, a exemplo da repercussão geral em Recurso Extraordinário.

Muito embora tenha o Pretório Excelso a boa vontade de dar maior agilidade ao sistema processual, é necessário que esse lembre que suas decisões tem de serem consolidadas em três aspectos: o material, forma e processual.

Assim, é inconcebível admitir que a Suprema Corte brasileira conceda efeitos erga omnes pela via de controle difuso, pois se assim o fizer gerará os seguintes três grandes problemas: primeiro, fará com que o Controle Concentrado perda o sentido de existir; segundo, será a sua transformação de "Guardião da Constituição" em poder constituinte perene; e terceiro, estará influenciando totalmente nas funções de legislador que coube ao Poder Legislativo desfazendo o próprio sistema de Separação dos Poderes.

É com este pensamento que conclui-se o presente trabalho, demonstrando que muito embora o constitucionalismo moderno avance no sentido de flexibilizar a rigidez da constituição para que esta sofra mutações ou o Poder Judiciário chame para si funções de outros Poderes, este conceito não poderá se adequar à Constituição Federal de 1988, uma vez que esta não permite que tais mudanças aconteçam, pois foi criada sob os pilares do Estado de Direito, como bem demonstram as cláusulas pétreas. Assim aceitar a Teoria da Abstrativização no sistema jurídico brasileiro é seguir em via inversa a dos princípios constitucionais.

Em suma, a existência de dois meios de Controle de Constitucionalidade demonstram que a incidência de um não pode se sobrepor ao outro, pois estes precisam coexistir. Devendo o STF ater-se apenas em manifestar suas decisões ao que lhe foi pedido.

Espera-se que, através deste pequeno escrito, seja possível contribuir para a informação dos leitores e o despertar de novos estudiosos para aprofundarem o tema.

\section{REFERÊNCIAS}

Supremo Tribunal Federal, Processo Administrativo 318.715, Brasília - DF, disponível em www.stf.jus.br. Acesso em 10.dez.2011;

. Supremo Tribunal Federal, Reclamação Constitucional 4335-5/AC, Brasília - DF,

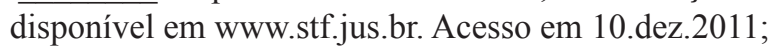

BRASIL. Códigos: Civil, Processo Civil e Constituição Federal. 3. ed. São Paulo: Saraiva, 2007. CANOTILHO, Joaquim José Gomes. Estado de Direito. Coimbra Editora, 2003;

LENZA, Pedro. Direito Constitucional esquematizado, São Paulo: Método, 2009.

MONTEIRO, P. H. D. A Abstrativização do Controle Difuso e o Precedente Vinculante. Revista dos Estudantes de Direito da Universidade de Brasília, n. 8, p. 228-258, 2009; 
CONSTITUTIONAL CONTROL AND ITS CONSEQUENCES IN BRAZILIAN LAW

Abstract: Due to a recent judgement from Brazil's Supreme Court, this article discusses the possibility of applying the same effects of the concentrated constitutional control, as ruled by specific law, on the diffuse constitutional control system.

Keywords: Constitutional Control. Concentrated Control. Diffuse Control. Abstractiveness. 